\title{
Tobacco sales in pharmacies: mixing good drugs and bad drugs
}

Tobacco products are instruments of death that simply do not belong in drug stores - whose very existence affirms the primacy of life. I believe that any drug store owner whose economic viability rests on the sale of tobacco products should give up his business and choose another field. The practice of pharmacy cannot co-exist with the selling of cigarettes. - JOHN PILGRIM. ${ }^{1}$

The American Pharmaceutical Association's code of ethics states that "A pharmacist should hold the health and safety of patients to be of first consideration... [and] should not engage in any activity that will bring discredit to the profession."2 Thus it should come as no surprise that the association has recommended since 1971 that tobacco products not be sold in pharmacies. ${ }^{3}$

Despite that policy, little progress has been achieved during the past two decades. Survey after survey has shown that tobacco products continue to be sold by the vast majority of pharmacies in the United States. A 1976 survey of 100 pharmacies in San Francisco showed that 89 sold cigarettes and 15 advertised cigarettes. ${ }^{4}$ In a survey in New Jersey in 1985 and 1986 all 89 large-chain pharmacies and $134(92 \%)$ of the 145 independent pharmacies sold tobacco products. ${ }^{5}$ A 1986 survey in Georgia found that all 41 chain pharmacies and $60(63 \%)$ of the 95 independent pharmacies sold cigarettes (A T Taylor et al, unpublished manuscript). In a 1991 survey of 100 pharmacies in Massachusetts 95 sold tobacco products and half of them displayed tobacco advertisements. ${ }^{6}$ More progress seems to have been made in Minnesota, a leader in tobacco control; in a survey of 400 pharmacists $60 \%$ of respondents (the survey had an $80 \%$ response rate) reported that their pharmacy practice site did not sell tobacco products (P J Martinez, written communication, 3 March 1991).

It is particularly egregious that pharmacies often sell tobacco products to minors. In their study in Massachusetts Brown and DiFranza found that $77(81 \%)$ of the 95 pharmacies that sold tobacco products were prepared to

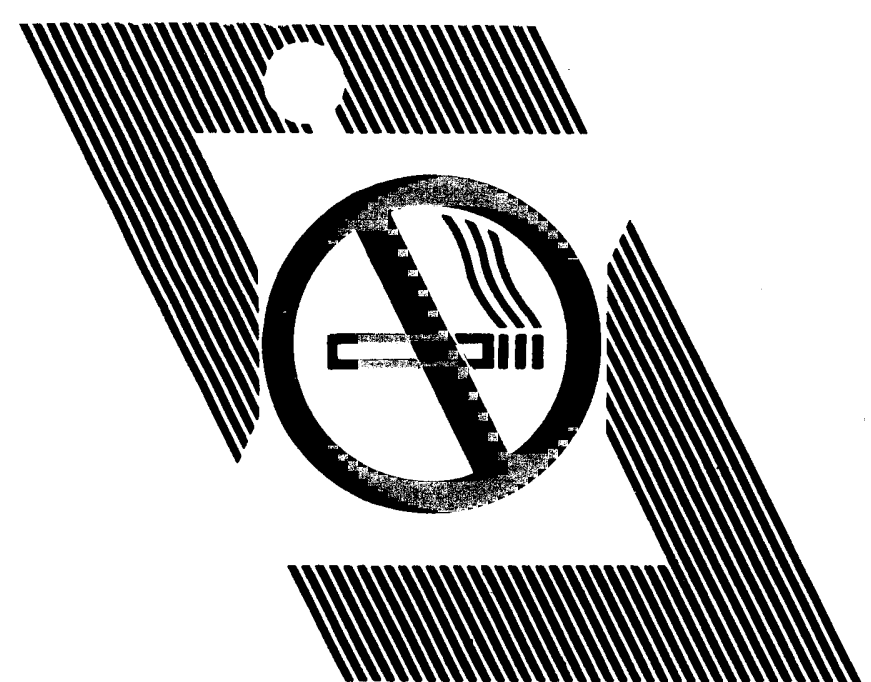

Logo of Pharmacists for NonSmoking Families (based in Henderson, Nevada) sell tobacco to underage buyers in sham purchases. When these authors combined their results with those of five smaller surveys performed in other states, they discovered that $68 \%(184 / 270)$ of tobacco selling pharmacies sold tobacco illegally to children. ${ }^{6}$ Furthermore, 22 of the 100 Massachusetts pharmacies sold confectionery tobacco products, which, according to recent evidence, may promote smoking experimentation among children.?

In a letter to the editor published in this issue of Tobacco Control Moreau and colleagues report that Canada, like the United States, is one of the few countries where tobacco products are sold in pharmacies. In a survey of 114 pharmacies in the Ottawa area Physicians for a SmokeFree Canada found that $66(58 \%)$ sold tobacco products, despite professional recommendations against such sales. ${ }^{8}$ In other cities in Canada a higher proportion of pharmacies sell tobacco products. ${ }^{9}$

\section{Initial steps}

What can be done to get tobacco out of pharmacies? The first step - the adoption of appropriate policy by pharmacists' associations - was taken long ago. The Canadian Pharmaceutical Association, like its American counterpart, issued an anti-tobacco appeal in the $1970 \mathrm{~s}^{10}$

A second step - continued education and exhortation has also occurred to a certain degree. In 1986 the American Pharmaceutical Association teamed up with the US National Cancer Institute to launch a programme called Helping Smokers Quit. ${ }^{11}$ It includes a guide for pharmacists, which, although avoiding the matter of tobacco sales in pharmacies, contains useful materials for pharmacists and their patients on smoking and drug interactions and how to stop smoking. The Canadian Pharmaceutical Association ran similar programmes in the $1980 \mathrm{~s}-$ the 1983 Stand Up and Be Counted programme and its successor programme, PACT\$ (Pharmacists Against Cigarette and Tobacco Sales). ${ }^{10}$ A few years ago John Pilgrim of Henderson, Nevada, founded an organisation called Pharmacists for NonSmoking Families, billed as "a nationwide effort to encourage independent pharmacists to remove tobacco products from their shelves, and steer clients towards safe, medically approved treatments for nicotine addiction."

The Michigan Pharmacists Association (MPA) is collaborating with the Michigan Department of Public Health $(\mathrm{MDPH})$ in a campaign to discourage pharmacists from selling tobacco products and to encourage them to educate their clients about the hazards of smoking and methods to quit. Coinciding with this effort, pharmacists at the Ferris State University College of Pharmacy in Big Rapids, Michigan, are developing a Pharmacists Assisting Smokers to Stop (PASS) programme and guide, funded by the American Association of Colleges of Pharmacy and the SmithKline Beecham Foundation.

The MPA/MDPH programme was launched at the Michigan Pharmaceutical Association's interim meeting in February 1992 with a seminar on the ethics of pharmacy tobacco sales and with recognition of a half dozen pharmacies in Michigan that don't sell tobacco. At the 
conference's exhibit hall Marion Merrell Dow and Lederle Laboratories were actively promoting their "nicotine transdermal systems" (also known as nicotine skin patches)-Nicoderm and ProStep, respectively. Other exhibitors included the American Cancer Society, the American Heart Association, the US Drug Enforcement

- Administration, the Michigan Substance Abuse and Traffic Safety Information Center, and the Michigan Department of Public Health (which displayed the materials from the National Cancer Institute and American Pharmaceutical Association programme). In the midst of all this, incredibly, Michigan Prescription - a pharmaceutical and tobacco distributor based in Pontiac, Michigan - was passing out Winston hats and promoting its full line of competitively priced cigarettes (see figure). Larry Wagenknecht, the executive director of the Michigan Pharmacists Association and the one who conceived the MPA/MDPH campaign, was caught offguard by the pro-tobacco pitch and assured me that it would not happen again. The imbroglio was a dramatic symbol of how little progress has been made to achieve tobacco-free pharmacies. But the palpable discord in the exhibit hall left me with the impression that tobacco sales in pharmacies will become increasingly untenable in the face of the current, unprecedented, and growing demand for a pharmacological smoking cessation aid (the nicotine skin patch). ${ }^{12}$

\section{From words to action}

Dissatisfied with the slow pace of voluntary action, the Ontario College of Pharmacists and l'Ordre des Pharmaciens du Québec have sought to ban tobacco sales in pharmacies. ${ }^{13}$ An Ontario task force has recommended that the provincial government ban tobacco sales in pharmacies by 1 July 1993 . In the meantime the college plans to accomplish a ban through the province's accreditation process for pharmacists. The ordre indicated an intention to prohibit pharmacy tobacco sales by amending the pharmacists' code of ethics, a change which must be approved by the provincial cabinet. Recently, however, the ordre has weakened its stance ( $M$ Taylor, personal communication, May 1992). Given that large pharmacy chains - especially those owned by tobacco companies ${ }^{8}-$ show little if any inclination to give up their nicotine dependence voluntarily, the use of legislation, regulation, or accreditation to ban tobacco sales in pharmacies is appropriate. 
Strategies to ban pharmacy tobacco sales have not been pursued seriously in the United States. Indeed, in a curious twist, Action on Smoking and Health (ASH) petitioned the US Food and Drug Administration in May 1977 to regulate cigarettes as a drug or medical device and to restrict their sale to pharmacies. Such a restriction, ASH argued, would make it more difficult for children to obtain cigarettes, would "serve as a graphic and dramatic reminder to the smoker that cigarettes are at least as dangerous as many prescription drugs," and "might provide an additional incentive for smokers to quit."

While pursuing bans on pharmacy tobacco sales we should revisit the proposal by Richards and Blum to support pharmacies that make a commitment to health promotion. ${ }^{14}$ Richards and Blum recommended that local medical societies establish a registry of pharmacies that refuse to sell tobacco products, to which physicians and other health care providers could direct their patients. One notable example of such action occurred in Washington State in 1986, when a group of local physicians began printing a message on prescription pads advising their patients not to have prescriptions filled at pharmacies that sell tobacco products. After pressure from the Clark County Medical Society, Hi-School Pharmacy discontinued tobacco sales at its 12 stores in Vancouver, Washington. ${ }^{1516}$

Here is where we should take a lesson from the tobacco industry, which throws its money around - or pulls it back - to achieve its aims. In 1990 Americans spent $\$ 54.6$ billion on drugs and other "non-durable" medical products, or $8.2 \%$ of total national health expenditures. ${ }^{17}$ Health care providers have all the financial leverage they need to rid pharmacies of tobacco. If pharmacy policies continue to be made based on "the bottom line," the solution - in the absence of a ban on pharmacy tobacco sales - is clearly to change the bottom line.

Editor

RONALD M DAVIS

1 Pilgrim J. What we're doing to help people quit smoking. The SmokeFree Pharmacy - A Newsletter from Pharmacists for NonSmoking Families Summer $1990 ; 2(1): 2$

2 American Pharmaceutical Association. Code of ethics, approved August 1969, amended December 1975, revised fuly 1981. Washington, DC: American Pharmaceutical Association.

3 Committee reports. Fournal of the American Pharmaceutical Association 1971; NS11 : 270 .

4 Schroeder SA, Showstack JA. Merchandising cigarettes in pharmacies: a San Francisco survey. Am $\mathcal{F}$ Public Health 1978; 68: 494-5.

5 Davidson L, Slade J, Stang CL. Knowledge and attitudes about tobacco among pharmacists who do and who do not sell tobacco. In: Aoki M, Hisamichi S, Tominaga S, eds. Smoking and health 1987, Proceedings of the 6th world conference on smoking and health, Tokyo, 9-12 November 1987. Amsterdam: Excerpta Medica, 1988: 343-5.

6 Brown LJ, DiFranza JR. Pharmacy promotion of tobacco use among children in Massachusetts. American Pharmacy 1992; NS32: 421-4.

7 Klein JD, Forehand B, Oliver J, Patterson CJ, Kupersmidt JB, Strecher V. Candy cigarettes: do they encourage children's smoking? Pediatrics 1992;89:1-5.

8 Moreau S, Taylor MC, Walker JD. Tobacco sales: Canadian pharmacies ignore professional recommendations. Tobacco Control 1992;1:138.

9 Taylor M, Walker J, Esdaile D, Goodyear M, Moreau S. The campaign to promote tobacco-free pharmacies. Nova Scotia Medical fournal 1990 69 (Oct): 156-7.

10 Reinboldt A. Is there a choice? Canadian Pharmaceutical fournal 1991; 124: 464,476

11 Everson J. Pharmacists get ammo in war on smoking: APhA/NCI publicize interactions of tobacco, drugs. American Medical News 18 July 1986 $17-8$.

12 Hwang SL, Valeriano LL. Marketers and consumers get the jitters over severe shortage of nicotine patches. Wall Street fournal 22 May 1992.81

13 Reinboldt A. Wrapped in red tape. Canadian Pharmaceutical fournal 1991 ; 124: 460-1.

14 Richards JW, Blum A. Pharmacists who dispense cigarettes: with reference to drug store chains and pharmaceutical companies. NY State $\mathcal{f} \mathrm{Med}$ $1985 ; 85: 350-3$

15 Bosy L. Pharmacy chain stops selling tobacco products. American Medical News 5 Dec 1986: 18.

16 Anonymous. With pressure from medical group, Wash. drug chain ban tobacco. US Tobacco and Candy fournal 9-29 Oct 1986:3.

17 Levit KR, Lazenby JC, Cowan CA, Letsch SW. National health expenditures, 1990. Health Care Financing Review $1991 ; 13(1): 29-54$. 